\title{
Splitting the Nucleus What's Wrong with the Tripartite Ring Model?
}

\author{
K. NASMYTH AND R.A. OLIVEIRA \\ Department of Biochemistry, University of Oxford, Oxford, OX1 3QU, United Kingdom \\ Correspondence: kim.nasmyth@bioch.ox.ac.uk
}

\begin{abstract}
The segregation of sister DNA molecules at mitosis involves their traction to opposite poles by microtubules attached to kinetochores. By creating tension required to stabilize kinetochore microtubules, sister chromatid cohesion has a key role in ensuring that sister kinetochores attach to microtubules with opposing polarity, a process known as biorientation. Cohesion is mediated by a cohesin complex whose Smc1, Smc3, and kleisin subunits form a tripartite ring thought to hold sister DNAs together by entrapping them (the ring model). Sister chromatid disjunction at the onset of anaphase is triggered by a thiol protease called separase whose activation, only when all chromosomes have bioriented, opens the cohesin ring by cleaving its kleisin subunit. Separase is inhibited by the binding of an inhibitory chaperone called securin whose destruction at the hands of a ubiquitin protein ligase called the anaphase-promoting complex/cyclosome (APC/C) is essential for kleisin cleavage and sister chromatid disjunction. We describe microinjection experiments showing that cohesin cleavage and Cdk1 down-regulation are sufficient to drive formation of daughter nuclei in cells arrested in metaphase due to inactivation of the APC/C and describe chemical cross-linking experiments consistent with the ring model. How sister DNAs enter the cohesin ring and are retained inside for long periods of time after the completion of DNA replication remains poorly understood.
\end{abstract}

Serious attempts to understand the organization of nuclei must account for how they reproduce, namely how the nuclei of dividing cells give rise to a pair of daughter nuclei shortly before cell division. Possibly the most significant insight into this remarkable process was the realization that unlike cells, nuclei do not undergo a constriction dividing them into two, known as "direct" division. They instead undergo a remarkable metamorphosis involving the appearance of nuclear threads that subsequently split longitudinally with each half moving to opposite poles of the cell before decondensing and nucleating the formation of daughter nuclei. This "indirect" process of nuclear division is now known as mitosis, the nuclear threads as chromosomes, and their progeny as sister chromatids. Although first described in beautiful detail by Flemming (1880), the potential significance of indirect nuclear division was first grasped by Wilhem Roux who suggested that it provided a mechanism for the nucleus to be divided not only quantitatively but also according to the mass and nature of its individual qualities (Roux 1883). We now know that Roux's “qualities" are conveyed largely by the sequence of nucleotides along the DNA molecules that form the backbone of each chromosome and specify the entire development of the organism.

The realization that DNA is composed of two nucleotide chains wound around each other forming a double helix that is replicated semiconservatively using WatsonCrick base pairing revealed the fundamental principle responsible for chromosome replication (Watson and Crick 1953). It did not, however, explain how the two products of this process, namely sister chromatids, unerringly move to opposite poles of the cell during mitosis, a phenomenon so universal and usually flawless that it has often been taken for granted and only in recent times acknowledged as a process lacking a satisfactory explanation. Defects in the segregation of chromatids during meiosis are responsible for human aneuploidy and for a large fraction of agerelated infertility in females (Hassold and Hunt 2001), whereas defects during mitosis contribute to the genomic instability of tumor cells.

An important but underappreciated step toward understanding how sister chromatids disjoin to opposite poles was the realization that they contain a single, albeit gigantic, DNA molecule. This was so surprising and unexpected that the evidence, in hindsight glaringly unambiguous, was initially not recognized for what it was worth, and a far more improbable, not to mention baroque, alternative favored. The classic experiment (Taylor et al. 1957), somewhat unjustly overshadowed by the work by Meselson and Stahl (1958), involved the use of tritiated thymidine to pulse-label DNA in proliferating bean shoot cells. As predicted by the semiconservative replication intrinsic to the Watson-Crick model, both chromatids of mitotic chromosomes produced after a round of DNA replication in the presence of the tritiated thymidine contained similar levels of the isotope. Remarkably, a subsequent round of replication in the absence of label (the chase) generated mitotic chromosomes in which one chromatid was labeled and one unlabeled, a result that is difficult if not impossible to explain without supposing that each chromatid is composed of a single DNA molecule. This interpretation was confirmed by comparing the kinetics with which the loops and central axes of lampbrush bivalent chromosomes were broken by DNase I, an enzyme that nicks one DNA strand at a time. Breaks in the loops accumulated with doublehit kinetics, consistent with a single double helix, whereas 
breaks in the central axis accumulated with quadruple-hit kinetics, consistent with the existence of two double helices (Gall 1963). The problem of chromosome segregation therefore boils down to how sister DNA molecules are pulled toward opposite poles by the microtubules of the spindle apparatus that attach to each molecule via specialized attachment sites known as kinetochores. This is known as the biorientation problem.

\section{SISTER CHROMATID COHESION RESISTS SPINDLE FORCES}

Appreciation of the role of sister chromatid cohesion in biorientation stemmed from experiments with meiotic cells in which the participants are not a pair of sister chromatids, as in mitosis, but instead bivalent chromosomes containing four chromatids interconnected by crossingover between nonsister homologous chromatids (Fig. 1). During meiosis I, sister kinetochores act as a single unit and the name of the game is to pull maternal and paternal sister kinetochore pairs in opposite directions. A beautiful series of experiments with grasshopper spermatocytes demonstrated that attachments leading to the erroneous traction of maternal and paternal kinetochores to the same pole in fact occur with some regularity but are invariably unstable and sooner or later replaced by more stable attachments in which maternal and paternal kinetochores are pulled in opposite directions, which is the desired outcome. This led to the proposal that biorientation, in this case of bivalent chromosomes, comes about by the selective stabilization of attachments that lead to tension. As predicted by this notion, erroneous attachments in which maternal and paternal kinetochores had attached to the same pole were stabilized by pulling the bivalent in the opposite direction with a tiny glass needle (Nicklas 1967).

If microtubules provide the force that pulls chromatids around the cell, the tension required for stable attachments can only be created by forces capable of countering those created by microtubules, namely cohesive forces that hold together sister chromatids and bivalent chromosomes during mitosis and meiosis, respectively. Note that it is not necessary to invoke two different types of cohesiveness during meiosis and mitosis because sister chromatid cohesion would suffice in both cases. What then after replication holds sister DNA molecules together in a manner capable of resisting spindle forces? The first coherent and serious proposal was the suggestion that cohesion is mediated by the intertwining of sister DNAs created during DNA replication (Murray and Szostak 1985), either by swivelling of replication forks driven by supercoiling ahead of them induced by unwinding the parental DNA strands (Lucas et al. 2001) or by rapid replication fork convergence (Sundin and Varshavsky 1981). Such intertwining or catenation is undoubtedly generated during $\mathrm{S}$ phase and its removal requires the action of topoisomerase II (Topo II) (Dinardo et al. 1984; Holm et al. 1985). The model proposed that a level of intertwining sufficient to hold sisters together persists until metaphase, whereupon a sudden burst of Topo II activity would remove the last vestiges and trigger sister chromatid disjunction. To explain the two-step removal of cohesion during meiosis, it was suggested that pericentric DNA was not replicated until meiosis II, whereupon a new wave of intertwining would generate sufficient cohesion at centromeres to drive the second meiotic division (Murray and Szostak 1985). This fascinating proposal had great merits because it provided a clear and testable explanation for the phenomenon of sister chromatid cohesion. It made a very strong prediction, namely that circular minichromosomes in yeast cells arrested in metaphase should be composed of catenated sister DNAs. An investigation revealed this not to be the case, dealing the hypothesis a major, although possibly not mortal, blow (Koshland and Hartwell 1987). The finding that Topo II is still required to decatenate chromosomal DNAs after metaphase (Holm et al. 1989) left open the possibility that catenation, although clearly insufficient to explain minichromosome segregation, might still have an important role in holding real chromatids together during mitosis. As we see below, there are grave doubts as to whether cohesion of this nature can on its own resist spindle forces. However, the catenation hypothesis has another major flaw. Any explanation for sister chromatid cohesion must not only provide a structural explanation for how sister DNAs are held together but must also explain how dissolution of cohesion is delayed until all chromosomes have bioriented (Miyazaki and Orr-Weaver 1994), a process now known as the spindle assembly checkpoint (SAC) (Musacchio and Salmon 2007). If sister chromatid disjunction were triggered by a burst of Topo II activity, the latter must be regulated by the biorientation process. However, to date there is no evidence for a regulatory pathway with these properties.
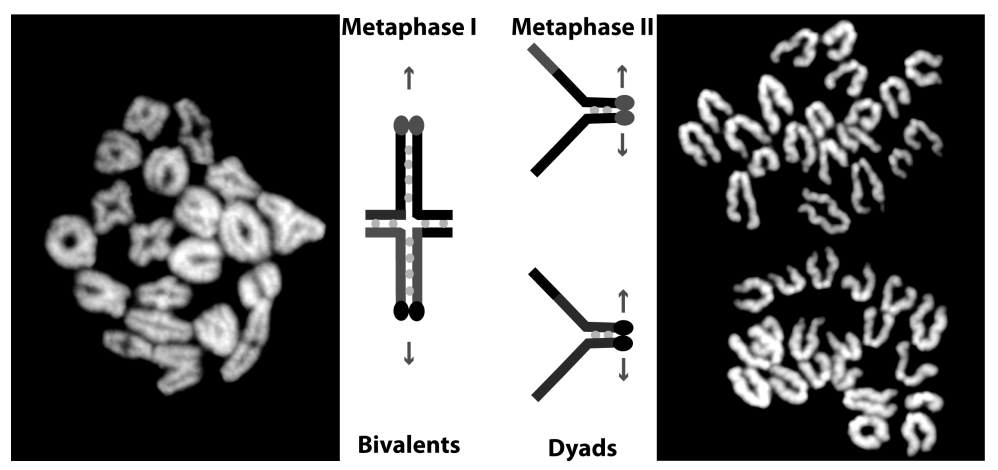

Figure 1. Meiotic chromosomes. Telocentric meiotic chromosomes from mice. (Left) Bivalent chromosomes created by recombination. (Right) Dyad chromosomes created by the selective destruction of sister chromatid cohesion along chromosome arms at meiosis I. 
If not a burst of Topo II activity, then what triggers sister chromatid disjunction and the onset of anaphase? This has been known to be a sudden and synchronous process ever since its first description. Thus, Flemming rarely saw "images of some of the segments being split while others are not," leading him to conclude that "the impetus that establishes the tendency for nuclear threads to split longitudinally acts simultaneously throughout the whole nuclear figure" (Flemming 1880). If biorientation during metaphase involves a "tug of war" between forces exerted by kinetochore-associated microtubules and cohesion between sister chromatids, disjunction could be driven by either loss of cohesion or a change in microtubule dynamics. As we see below, both occur at the onset of anaphase. There were two reasons for believing that loss of cohesion might have a key role. In plant cells treated with spindle poisons such as colchicine, all sister chromatids are observed to disjoin suddenly and synchronously in the total absence of microtubules (Mole-Bajer 1958). Needless to say, the chromatids do not subsequently move toward the poles but remain side by side. This process, known as $\mathrm{C}$ mitosis and widely used for diploidization of haploid cell lines in plant breeding, comes about because the SAC cannot delay the disjunction process for very long in these cells. A second reason is that when one of the kinetochores of a late-prometaphase chromosome is destroyed by a laser beam, the chromosome moves with the velocity of an anaphase chromosome toward the pole to which the nonirradiated kinetochore is connected (Nicklas 1988; Rieder 1991). If the forces acting on kinetochores do not appear to increase greatly as cells enter anaphase (Miyazaki and Orr-Weaver 1994), then something else, presumably a loss of cohesion, must trigger disjunction.

\section{IDENTIFICATION OF THE ANAPHASE TRIGGER: THE APC/C}

What then is Flemming's "impetus" for sister chromatid disjunction? Our first insight into molecular events at this stage of the cell cycle was the finding that the mitotic cyclin regulatory subunits of the $\mathrm{Cdk} 1$ protein kinase responsible for triggering mitotic entry are suddenly degraded at the metaphase-to-anaphase transition (Evans et al. 1983). The finding that expression of nondegradable cyclin variants blocked the metaphase-to-anaphase transition in Xenopus extracts suggested that mitotic control might be beguilingly simple, namely Cdk1 activation triggers entry whereas inactivation due to cyclin degradation triggers the metaphaseto-anaphase transition (Murray et al. 1989). This appealing paradigm was subsequently overturned by the findings that unphysiologically high levels of nondegradable cyclins are required to block anaphase in Xenopus extracts (Holloway et al. 1993) and more serious, even very high, levels have no effect whatsoever on anaphase in yeast (Surana et al. 1993). That Cdk1 inactivation per se does not trigger anaphase is graphically demonstrated by experiments in which fly embryos arrested in metaphase are injected with a bolus of the potent and highly specific Cdk1-inhibitory protein p27 (Fig. 2A), which triggers mitotic exit but not sister chromatid disjunction (Oliveira et al. 2010).
Although it is not the actual trigger for anaphase, cyclin's rapid degradation at the metaphase-to-anaphase transition led to attempts to identify the apparatus responsible for this remarkable proteolytic event. Biochemical experiments with extracts from Xenopus (Glotzer et al. 1991) and clam (Hershko et al. 1991) suggested that cyclin destruction was accompanied by and dependent on cyclin ubiquitinylation, a process that in addition to ubiquitin activating and conjugating enzymes required a huge 20S ubiquitin protein ligase (King et al. 1995; Sudakin et al. 1995), initially called the cyclosome. Genetic experiments with yeast had meanwhile identified genes specifically required for cyclin degradation (Irniger et al. 1995) that encoded subunits of the ligase (King et al. 1995; Zachariae and Nasmyth 1996; Zachariae et al. 1996). Strikingly, the yeast studies demonstrated that the cyclin ubiquitin protein ligase was not only intimately involved in cyclin degradation but also essential for the metaphaseto-anaphase transition. Temperature-sensitive mutants arrest uniformly in metaphase (Culotti and Hartwell 1971; Irniger et al. 1995), a phenotype that could not be explained by their defective cyclin degradation (Surana et al. 1993). The implication was that the ubiquitin protein ligase responsible for cyclin degradation had other targets whose destruction, unlike that of cyclins, was essential for anaphase. It is for this reason that the ligase, now known to contain 15 or more subunits, is known as the anaphasepromoting complex/cyclosome (APC/C) (Peters 2006).

\section{APC/C TRIGGERS ANAPHASE BY DESTROYING SECURINS}

Could anaphase be triggered through destruction by the APC/C of a single key protein besides a cyclin? Candidates for such a protein emerged again from yeast genetic studies. In budding yeast, mutations in a nonessential gene called PDS1 caused a loss of viability, that was accompanied by a loss of sister chromatid cohesion, in cells arrested in a mitotic state by spindle poisons (Yamamoto et al. 1996b). Like cyclins, the Pds1 protein is dramatically degraded in an APC/C-dependent fashion at the metaphase-to-anaphase transition but, unlike cyclins, expression of a nondegradable version blocks sister chromatid disjunction (Cohen-Fix et al. 1996). More remarkable still, inactivation of Pds1 allows yeast cells lacking APC/C activity to disjoin sister chromatids (Yamamoto et al. 1996b; Ciosk et al. 1998). What turns out to be Pds1's ortholog in fission yeast is a gene known as Cut2 that was paradoxically identified not because it inhibits anaphase but because it is required for this process along with a protein called Cut1 with which it was found to coprecipitate (Funabiki et al. 1996a). Like Pds1, destruction of Cut2 at the hands of the APC/C is essential for sister chromatid separation (Funabiki et al. 1996b). Strangely, Pds1 and Cut2 share little sequence similarity and it was initially unclear whether they were orthologous proteins with homologous functions. However, this conundrum was resolved when purification of Pds1 revealed that it was bound in a stoichiometric fashion with a protein called Esp1 (Baum et al. 1988) that was clearly homologous to Cut1 (Uzawa et 
A
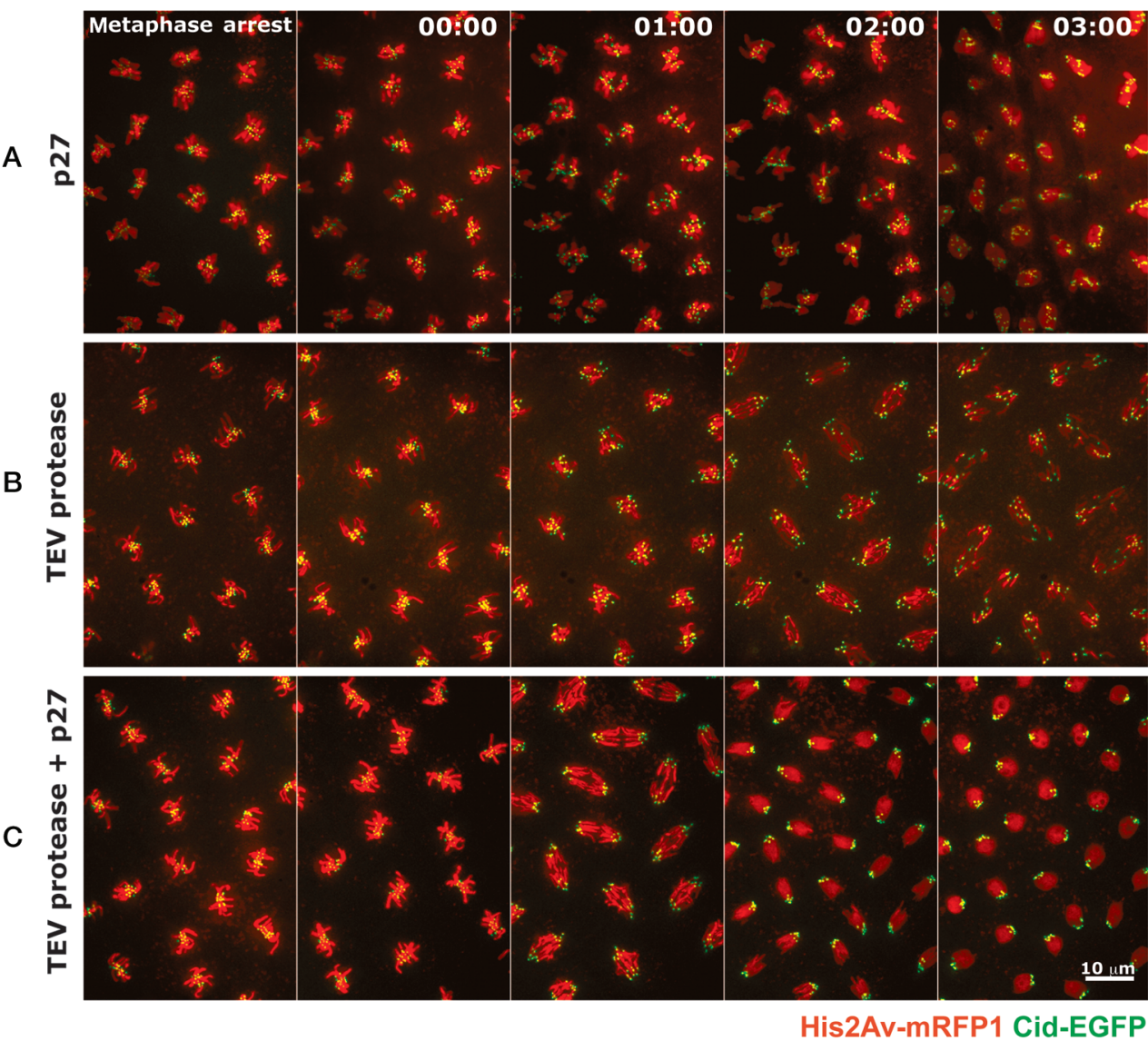

Figure 2. Artificial mitosis. Drosophila embryos expressing solely TEV-sensitive cohesin complexes were arrested in metaphase (by injection of $\left.\mathrm{UbcH} 10^{\mathrm{C} 114 \mathrm{~S}}\right)$ and subsequently injected with the Cdk inhibitor $\mathrm{p} 27(A)$, TEV protease $(B)$, or TEV protease together with p27 (C) (for details, see Oliveira et al. 2010).

al. 1990) and, like the latter, essential for sister chromatid separation (McGrew et al. 1992; Ciosk et al. 1998). The picture emerging from these studies was the notion that by destroying Pds1/Cut2-like proteins, now known to be universal and known as securins, the APC/C destroyed an inhibitor of a protein (Esp1/Cut1) that catalyzed sister chromatid disjunction (Ciosk et al. 1998).

\section{COHESINS: CHROMOSOMAL PROTEINS ESSENTIAL FOR SISTER CHROMATID COHESION}

What then is the mechanism by which securins inhibit sister chromatid disjunction? Moreover, why, if they are inhibitors, are securins also necessary for sister chromatid disjunction in certain organisms? The observation that securins and their Esp1/Cut1 partners associate with mitotic spindles (Funabiki et al. 1996a) appeared to resurrect the notion that anaphase might after all be triggered by changes in spindle dynamics. As we see below, they do indeed regulate spindle dynamics but in a manner that merely facilitates anaphase chromosome movements but does not trigger sister chromatid disjunction per se. When it was found that DNA catentation could not explain minichromosome cohesion (Koshland and Hartwell 1987), it was postulated that proteins might perform this function. Might securins be these hitherto elusive proteins? There were two major problems with this. First, in budding yeast and in many other organisms including mammals, securin is not essential (Yamamoto et al. 1996a; Wang et al. 2001). Although not known for sure at the time, it was thought that sister chromatid cohesion would be essential for mitosis. A second problem was that chromosome spreads indicated that securin is not stably associated with chromatin at any stage of the cell cycle, including in postreplicative cells (Ciosk et al. 1998).

The actual function of securins and their Esp1/Cut1 partners only emerged once the proteins that really do hold sisters together had been identified, again through genetic studies. The first identified chromosomal protein required for sister chromatid cohesion was Mei-S332, which is necessary for maintaining cohesion at centromeres following the first meiotic division (Baker et al. 1978; Goldstein 1980; Kerrebrock et al. 1995; Moore et al. 1998). Orthologs of Mei-S332, now known as shugoshins, exist in all eukaryotes (Kitajima et al. 2004; Marston et al. 2004; Rabitsch et al. 2004). It turns out that they are not part of the actual apparatus holding sisters together but rather are regulators of the process by which cohesion is destroyed during mitosis 
(Salic et al. 2004; McGuinness et al. 2005) and meiosis (Xu et al. 2009; Ishiguro et al. 2010; Katis et al. 2010).

Proteins more intimately involved in the physical process of holding sisters together were in fact found by yeast genetics. A search for temperature-sensitive mutants that mis-segregated chromosomes at low temperatures but were completely defective in mitosis at high temperatures, and separated sisters without having destroyed securin, led to the identification of four genes essential for sister chromatid cohesion: SCC1/MCD1, SCC2, SMC1, and SMC3 (Michaelis et al. 1997). SCC1/MCD1 was simultaneously identified in an independent screen for mutants that lose viability and separate sister chromatids in cells arrested in mitosis by nocodazole (Guacci et al. 1997). A subsequent screen revealed two more, namely SCC 3 and ECO1 (Toth et al. 1999). Unlike securin, one of the proteins encoded by these genes, Scc1, was found to be stably associated with chromatin from late $\mathrm{G}_{1}$ until the onset of anaphase, whereupon it disappeared from chromosomes completely (Michaelis et al. 1997). Subsequent biochemical experiments showed that the products of SCC1, SCC 3, SMC1, and $S M C 3$ form a multisubunit complex called cohesin (Losada et al. 1998; Toth et al. 1999) that also contains the Pds5 (Hartman et al. 2000; Panizza et al. 2000) and Wapl/Rad61 proteins (Gandhi et al. 2006; Kueng et al. 2006). Scc2 was meanwhile found to bind the protein Scc4, forming a stoichiometric complex essential for cohesin's stable association with chromatin (Ciosk et al. 2000). The mammalian orthologs of Scc2 and Scc4 are also known as Nipbl (Krantz et al. 2004; Tonkin et al. 2004) and Mau2 (Seitan et al. 2006; Watrin et al. 2006), respectively. Eco1, also identified as Ctf7 (Skibbens et al. 1999), is now known to control cohesion by acetylating cohesin's Smc3 subunit (Ivanov et al. 2002; Ben-Shahar et al. 2008; Unal et al. 2008; Rowland et al. 2009). Eco1 has two mammalian orthologs, namely ESCO1 and ESCO2 (Vega et al. 2005). In animal cells, the protein sororin is also required to build cohesion at $\mathrm{S}$ phase (Rankin et al. 2005; Schmitz et al. 2007).

\section{CLEAVAGE OF COHESIN'S SCC1 SUBUNIT BY SEPARASE TRIGGERS SISTER SEPARATION}

A crucial step in unraveling the mechanism of sister chromatid disjunction was the finding that the dramatic disappearance of Scc1 from chromosomes at the metaphase-to-anaphase transition requires not only the APC/C but also Esp1 (Ciosk et al. 1998), the partner of the APC/C's target securin. This led to the notion that Esp1 and not the APC/C is responsible for removing cohesin from chromosomes. By controlling degradation of securin, the APC/C's role in the process is to regulate Esp1 activity. The real breakthrough was the subsequent discovery that Esp1 is a site-specific protease that removes cohesin from chromosomes by inducing cleavage of Scc1 and that its enzymatic activity is inhibited by securin binding (Uhlmann et al. 1999, 2000). With the realization that all eukaryotes possess such enzymes (Waizenegger et al. 2000), orthologs of Esp1/Cut1 are now known as sepa- rases. Securin is not merely an inhibitor because its prior association with separase appears to be necessary for efficient activation following securin destruction, a phenomenon that is more acute in some organisms such as fission yeast (Funabiki et al. 1996a) and Drosophila (Stratmann and Lehner 1996), where, unlike budding yeast and mammals, securin is essential for sister chromatid disjunction. Another important detail that has emerged is that in vertebrates (but not in yeast) separase is inhibited by phosphorylation by cyclin B/Cdk1 (Stemmann et al. 2001) as well as by the binding of securin. In most cell types, neither one nor the other mechanism is essential, but inhibition by $\mathrm{Cdk} 1$ is crucial at certain stages of germline development (Huang et al. 2008, 2009), possibly due to lower securin concentrations.

Importantly, both mechanisms regulating separase are controlled by the $\mathrm{APC} / \mathrm{C}$ whose activation triggers the simultaneous ubiquitinylation of securin and cyclin B. It remains unclear as to exactly how $\mathrm{Cdk} 1$ inactivation leads to the rapid dephosphorylation of separase and whether this process involves up-regulation of phosphatases such as PP2A. Crucially, the APC/C and hence separase activity is regulated by the $\mathrm{SAC}$, ensuring that the process of sister chromatid disjunction is not triggered until all chromosomes have bioriented. This occurs through the formation of complexes between Cdc20 and SAC proteins such as $\mathrm{Mad}$, a process that is under control of kinetochores that have not connected to microtubules in a manner giving rise to tension (Musacchio and Salmon 2007). Thus, the APC/C-separase-cohesin pathway provides a coherent explanation for how cells regulate the disjunction process, in particular Flemming's seminal observation that sister chromatids disjoin synchronously, soon after biorientation of all chromosomes is complete, and not one by one.

\section{ARTIFICIAL MITOSIS}

If cohesin alone holds sister chromatids together and if its cleavage is the sole trigger for their disjunction, it should be possible to bypass the APC/C and reproduce at least certain aspects of the metaphase-to-anaphase transition by cleaving Scc1 using a foreign protease. Such experiments initially performed in yeast (Uhlmann et al. 2000) have recently been repeated in early embryos from Drosophila, where, unlike yeast, the consequences have been observed using real-time imaging (Oliveira et al. 2010). Embryos whose Scc1 protein (known in the fly as Rad21) contains TEV cleavage sites in addition to those recognized by separase were first arrested in metaphase by injection of a dominant negative version of $\mathrm{Ubc} 10$ (UbcH10 ${ }^{\mathrm{C} 114 \mathrm{~S}}$ ) the ubiquitin-conjugating enzyme used by the APC/C (Townsley et al. 1997). Subsequent injection of TEV triggered sister chromatid disjunction but not their orderly movement to opposite spindle poles. Indeed, after their initial disjunction, individual chromatids frequently reversed their direction of travel, moving back and forth in an aimless dance on the mitotic spindle (Fig. 2B). Thus, cohesin cleavage alone is sufficient to trigger disjunction but not the orderly segregation of chromatids. Similarly erratic chromosome segregation is observed in embryos 
expressing nondegradable cyclin B (Parry and O'Farrell 2001; Parry et al. 2003).

In addition to demonstrating the crucial importance of cohesin in holding sisters together, this experiment reveals that the $\mathrm{APC} / \mathrm{C}$ has functions in orchestrating chromatid segregation besides inducing cohesin cleavage. What might these be? If kinetochore microtubules are stabilized by tension, what happens when tension is destroyed by cohesin cleavage? The chaotic movement of chromatids following TEV cleavage implies that this class of microtubules is destabilized, with kinetochores reverting to a state in which new attachments are continually made and rebroken. The Aurora B kinase associated with centromeres has a key role in destabilizing kinetochore microtubules during prometaphase and is thought to cease doing so following the creation of tension (Tanaka et al. 2002; Ciferri et al. 2008; Liu et al. 2009). When anaphase is triggered in a physiological manner by the $\mathrm{APC} / \mathrm{C}$, one of the many changes that occur besides the loss of cohesion is the translocation of Aurora $\mathrm{B}$ from centromeres to the midzone of the mitotic spindle (Adams et al. 2001). This movement may have two or more crucial functions: prevent Aurora B from destabilizing kinetochore microtubules following the loss of tension caused by cohesin cleavage, inactivate the SAC, and stabilize the spindle midzone during the second phase of anaphase when poles themselves move apart. Interestingly, the anaphase-specific translocation of Aurora B fails to take place when cohesin is cleaved in cells lacking APC/C activity (Oliveira et al. 2010) and its persistence at centromeres could be responsible for the destabilization of kinetochore microtubules.

Another crucial function of the APC/C during anaphase may be to regulate, albeit indirectly, the SAC. If, as postulated, the tension that stabilizes kinetochore microtubule interactions also turns off the SAC, then cells must possess a mechanism that prevents SAC reactivation following the sudden loss of tension induced by cohesin cleavage. Such reactivation would enable $\mathrm{APC} / \mathrm{C}$ targets such as cyclin to reaccumulate and prevent efficient mitotic exit. Silencing of the SAC as chromosomes biorient and come under tension is accompanied by a major reduction in the concentration of SAC proteins such as BubR1 at kinetochores, and there is therefore little BubR1 associated with kinetochores in the embryos arrested in metaphase by injecting $\mathrm{UbcH} 10^{\mathrm{C} 114 \mathrm{~S}}$. However, the loss of cohesion triggered by injection of TEV leads to Bub1R's immediate reassociation with kinetochores, suggesting that the sudden loss of tension does indeed reactivate certain aspects of the SAC (Oliveira et al. 2010). A similar conclusion has been drawn from work on yeast (Mirchenko and Uhlmann 2010) and tissue culture cells (Vazquez-Novelle and Petronczki 2010).

The TEV cleavage experiments demonstrate that cohesin cleavage is sufficient to trigger sister chromatid disjunction but not other important properties of normal anaphase cells. The APC/C is known to induce destruction of several proteins at the onset of anaphase besides securin and cyclin B. The polo-like kinases (Shirayama et al. 1998; Lindon and Pines 2004) and Mps1 kinases are good examples (Palframan et al. 2006). Nevertheless, might destruction of just securin and cyclin B be sufficient to orchestrate a normal anaphase, as suggested by genetic ablation experiments in yeast (Shirayama et al. 1999)? If so, it ought to be possible to mimic the APC/C merely by injecting TEV to cleave cohesin and p27 to inhibit Cdk1. As described above, TEV alone triggers disjunction but not orderly anaphase chromosome movement, whereas p27 alone causes mitotic exit without any semblance of chromosome segregation. What happens when both proteins are coinjected? Remarkably, this induces chromosome segregation and the subsequent formation of daughter nuclei with kinetics and appearance that are almost indistinguishable to normal divisions (Fig. 2C) (Oliveira et al. 2010). Chromosomes segregate to the poles at normal velocities, Aurora B translocates from centromeres to the spindle midzones, and BubR1 remains absent from anaphase kinetochores, all in the complete absence of any APC/C activity. In other words, manipulation of just two key molecules, cohesin and Cdk1, is sufficient for the fission of eukaryotic nuclei. A corollary is that Cdk1 down-regulation at the metaphase-to-anaphase transition does not merely trigger exit from mitosis but alters kinetochore microtubule dynamics and the SAC so that they become refractory to the loss of tension caused by cohesin cleavage, as originally suggested from the results of expressing nondegradable cyclin B (Parry et al. 2003).

The TEV experiments also prove once and for all that it is cohesin and very probably cohesin alone that resists the spindle forces that attempt to disjoin bioriented chromosomes. They prove that in cohesin's absence, DNA catenation (Murray and Szostak 1985; Yanagida 2009), the origin recognition complex (Shimada and Gasser 2007), or condensin cannot perform this function (Lam et al. 2006). They also contradict the mischievous recent suggestion that "the loss of cohesin might not trigger anaphase per se, but that cohesin might be just one of many unwanted components that are removed from mitotic chromosomes to allow the progression of mitosis" (Yanagida 2009). Biology grapples with explaining complex physiological processes in terms of simple physical and chemical principles. An important criterion for evaluating success is whether the process can be reproduced by artificial means. There is a long history of this approach, which now comes under the rubric of synthetic biology. The induction of an event as dramatic as nuclear division merely by cleaving cohesin and down-regulating Cdk1 is surely a good example.

\section{THE COHESIN RING MODEL}

How does cohesin hold sister chromatids together and how does cleavage of its Scc1 subunit, either by separase or by TEV protease, destroy the linkage so rapidly? The peculiar quaternary structure adopted by three of its core subunits, namely Smc1, Smc3, and Scc1, has shed important insight. Smc1 and Smc3 fold back on themselves to form 50-nm-long intramolecular antiparallel coiled coils, forming rod-shaped proteins with globular "hinge" domains at one end (composed of sequences from the middle of the proteins) and an ABC-like ATP-binding domain (NBD) at the other end (composed of their amino- and carboxy-terminal globular domains). Heterotypic interac- 
tions between Smc1 and Smc3 hinges create stable Vshaped Smc1/Smc3 heterodimers (Melby et al. 1998; Haering et al. 2002; Hirano and Hirano 2002) that are converted to closed rings by the interconnection of their NBDs by cohesin's Scc1 subunit, whose amino- and carboxy-terminal domains bind to Smc3 and Smc1, respectively (Haering et al. 2002; Gruber et al. 2003). Because of their ability to create closed rings, the superfamily of Scc1-like proteins are known as kleisins, after the Greek $\mathrm{K} \lambda \varepsilon 1 \sigma 1 \mu \mathrm{O}$, meaning closure (Schleiffer et al. 2003). Scc1 and its meiotic variant Rec 8 belong to the $\alpha$-kleisin subgroup. Cohesin's ring-shaped structure is shared by the condensin complex, which contains a different pair of Smc proteins, namely Smc2 and Smc4, whose NBDs are connected by $\beta$ or $\gamma$ kleisins (Hirano 2005), and homodimeric bacterial complexes whose NBDs are also connected by kleisins at least at certain phases of their nucleotide-binding/hydrolysis cycle (Woo et al. 2009).

In addition to their kleisin-mediated interconnection, Smc1 and Smc3 NBDs can directly engage each other in the presence of ATP in a process involving interaction of phosphates of ATP bound to one head interacting with "signature" motifs on its partner. Only when engaged in this manner can the two ATP molecules sandwiched between Smc1 and Smc3 NBDs be hydrolyzed (Hopfner and Tainer 2003; Arumugam et al. 2006), a process that is essential for cohesin's stable association with chromosomes (Arumugam et al. 2003; Weitzer et al. 2003). Cohesin therefore forms two types of ring: a bipartite ring in which Smc1 and Smc3 NBDs are brought together by ATP, a process that depends on the binding of Scc1's carboxyterminal winged helical domain to Smc1's NBD (Arumugam et al. 2006), and a tripartite ring in which the Smc1 and Smc3 NBDs are bound by the carboxy- and amino-terminal domains of Scc1, respectively. The intervening central domain contains separase cleavage sites, either toward amino- or carboxy-terminal ends, and residues within the carboxy-terminal half that recruit Scc3 (Haering et al. 2002). How the Pds5/Wapl subcomplex associates with cohesin is poorly understood.

The discovery that cohesin's Smc and kleisin subunits form a tripartite ring led to the proposal that sister chromatid cohesion is conferred by entrapment of sister DNAs within (Fig. 3) (Nasmyth 2001; Haering et al. 2002; Gruber et al. 2003). The fact that cohesion is destroyed within seconds of its kleisin subunit being cleaved, possibly at any point within the latter's central domain, implies that stable entrapment depends on the three sets of interactions that create tripartite rings and not merely on the $\mathrm{Smc} 1 / \mathrm{Smc} 3$ hinge and Smc1/Smc3 NBD interactions that create bipartite rings. The suggestion that bipartite ring interactions alone hold sisters together (Weitzer et al. 2003) provides no explanation for how cleavage destroys the linkage instantaneously. Förster resonance energy transfer (FRET) studies suggest that most Smc1 and Smc3 NBDs are in close proximity (Mc Intyre et al. 2007). Because this association occurs throughout the cell cycle, even after Scc1 cleavage during anaphase and in its complete absence during early $\mathrm{G}_{1}$, the association between NBDs measured by FRET presumably corresponds to a weak one that is inca-

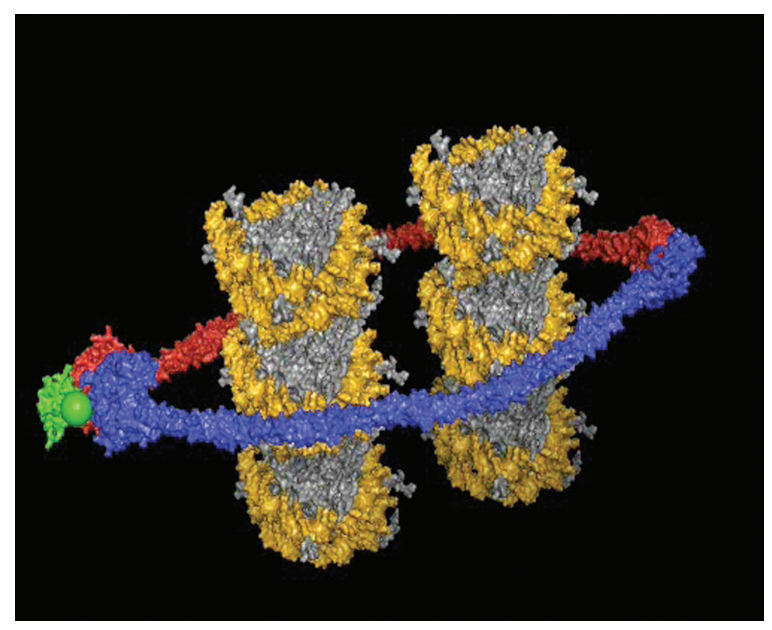

Figure 3. Cohesin ring model shows how cohesin rings could topologically embrace two 10 -nm chromatin fibers.

pable of preventing escape of DNAs from the ring following Sccl cleavage. In other words, the bipartite rings detected by FRET that persist after Scc1 cleavage cannot possibly confer cohesion. If the FRET studies are to be believed, the NBDs even of tripartite rings spend most of their time in close proximity. Nevertheless, unlike the interconnection of Smc NBDs by Scc1, this association is presumably not stable enough to prevent DNAs from escaping.

\section{TESTING THE TRIPARTITE RING MODEL}

As predicted by the tripartite ring model, association between cohesin and chromatin is destroyed both in vivo and in vitro not only by cleavage at any position within Scc1's central domain but also by severance of Smc3's coiled coil (Uhlmann et al. 1999; Gruber et al. 2003; Pauli et al. 2008). Equally telling, the association between cohesin and minichromosomes is destroyed in vitro by DNA cleavage, consistent with cohesin sliding off the ends of short linear chromatin fibers (Ivanov and Nasmyth 2005). The most rigorous test of the model has come from chemical cross-linking studies (Haering et al. 2008). If sister DNAs are entrapped inside a single tripartite ring, the generation of cross-links between Smc1 and Smc3 hinges and between amino- and carboxy-terminal domains of Scc1 and Smc3 and Smc1 NBDs, respectively, should entrap sister circular minichromosome DNAs inside a chemically circularized ring in a manner that would resist its denaturation by an ionic detergent such as sodium dodecyl sulfate (SDS). Instead of migrating as monomers in agarose gels, sister DNAs should migrate as an unusual type of dimer, namely one composed of a pair of monomeric DNAs catenated by a chemically circularized cohesin ring.

Three key preconditions were required to be met to perform this experiment. The first was the use of differential sedimentation velocity in sucrose gradients combined with differential agarose gel electrophoresis to separate monomeric from dimeric minichromosomes bound together by cohesin (Ivanov and Nasmyth 2007). The second was the determination by X-ray crystallography of the atomic struc- 
ture of two of the tripartite ring's three interfaces, namely the Smc hinge (Haering et al. 2002) and the Smc1NBD/ Scc1 complex (Haering et al. 2004). These structures enabled the replacement by cysteine of specific residues on either side of the two interfaces, creating cysteine pairs $5 \AA$ apart that could be cross-linked in a highly specific manner by a bifunctional thiol-specific chemical cross-linker such as dibromobimane. The third precondition was the discovery that cotranslational fusion of Smc3's carboxyl terminus to Scc1's amino terminus does not destroy cohesin function (Gruber et al. 2006), enabling 100\% cotranslational crosslinking without having to introduce cysteines into an interface whose atomic structure remains unknown.

By these three means, it was possible to isolate either monomeric or dimeric minichromosomes and then crosslink (with a combined efficiency approximating 35\%) the hinge, Smc1-Scc1, and Smc3-Scc1 interfaces of tripartite rings associated with them. In the absence of any introduced cysteines, the DNAs of both monomeric and dimeric minichromosome fractions from sucrose gradients run as monomers in agarose gels after the cross-linking procedure and denaturation in $1 \% \mathrm{SDS}$ at $65^{\circ} \mathrm{C}$. However, when isolated from cells whose cohesin subunits contain all four cysteines, $\sim 40 \%$ run somewhat more slowly than do DNADNA concatemers, implying that monomeric DNAs have been catenated by the chemically circularized cohesin rings (Fig. 4). Crucially, this only occurs when all four cysteines are present (Haering et al. 2008). It is difficult if not impossible to explain these results without supposing that the cohesion that holds minichromosomes together following their isolation in sucrose gradients is mediated by tripartite cohesin rings that have entrapped DNAs. By far the simplest explanation of these results is that sister DNAs are entrapped within monomeric tripartite rings, very possibly just one per minichromosome (Haering et al. 2008). However, it is just conceivable that they are instead entrapped
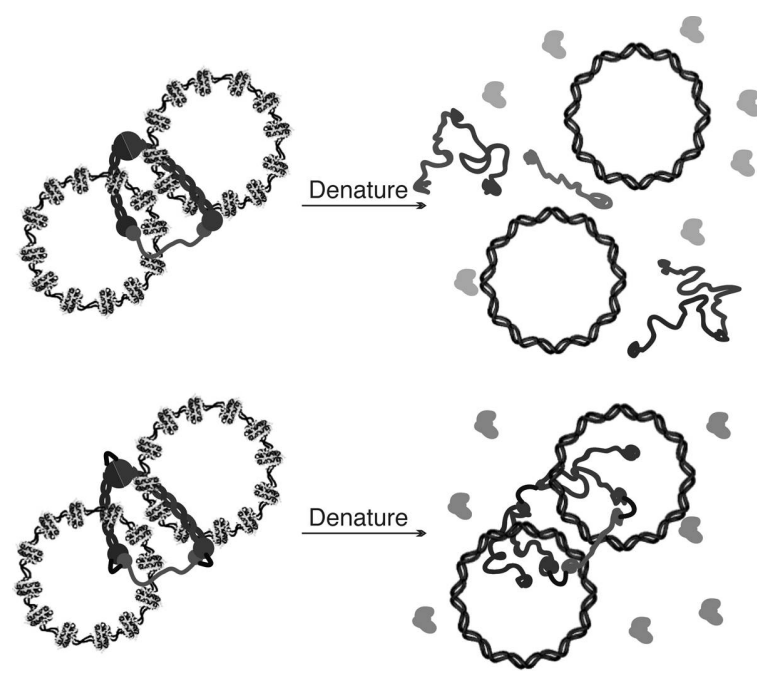

Figure 4. Testing the ring model. Circular DNAs held together by cohesin lose cohesion following protein denaturation. The ring model predicts that they will remain attached if the three interfaces creating the tripartite ring are chemically cross-linked (for details, see Haering et al. 2008). by dimeric rings in which Smc NBDs bind to Scc1 molecules whose amino- and carboxy-terminal domains are bound to different $\mathrm{Smc1/Smc3}$ heterodimers or that they are individually entrapped by two separate rings that are themselves catenated. However, in the case of these two more implausible scenarios, the comigration of sister DNAs would require simultaneous cross-linking of all four interfaces containing cysteine pairs as opposed to just two in the simpler case of monomeric rings. Importantly, the fraction of DNAs catenated by circularized cohesin was approximately the same as the predicted degree of circularization of monomeric rings and several-fold higher than the predicted degree of circularization of dimeric rings. Dimeric rings could only have given rise to the observed results if each dimeric minichromosome isolated from sucrose gradients contained several cohesive structures. Crucially, the results are inconsistent with so-called handcuff models, according to which each sister is entrapped by separate rings interacting with each other in a nontopological manner. For example, it has been suggested that individual Scc3 molecules bind simultaneously to two molecules of Scc1, each part of separate tripartite rings that have entrapped different (sister) DNAs (Zhang et al. 2008b). According to this model, cross-linking merely the tripartite ring's three interfaces could not possibly produce DNAs catenated by circularized cohesin rings, but it does!

\section{SO WHAT'S WRONG WITH THE RING MODEL?}

Notwithstanding residual doubts as to whether they totally exclude double rings, the cross-linking experiments imply that some if not most minichromosome DNAs isolated as dimers on sucrose gradients are entrapped inside tripartite cohesin rings, raising the possibility that this is the principle governing sister chromatid cohesion. Despite their unequivocal nature, the cross-linking studies have not prevented continued speculation that cohesin holds sisters together by forming unspecified interactions between two or more cohesin complexes (Zhang et al. 2008b; Yanagida 2009; Heidinger-Pauli et al. 2010; Skibbens 2010), even though such models cannot possibly explain the minichromosome observations. The implication implicit in such suggestions is that entrapment of minichromosomes by cohesin rings is either a complete artifact that has no bearing whatsoever on the actual mechanism of cohesion or a property that mediates a form of cohesion responsible for holding minichromosomes together in vitro but not cohesion of real chromosomes in live cells or in organisms other than budding yeast.

Are there in fact reasonable grounds for ignoring the minichromosome cross-linking results? One could argue that cohesion generated by complexes with Smc3 fused to Scc1, a feature essential for the cross-linking experiments, might have very different properties from those of wildtype complexes. Thus, despite the attractive feature of providing an explicit and testable explanation for cohesion, entrapment of chromatin fibers inside cohesin rings might be caused by the protein fusion required to perform the key cross-linking experiments. The flaw in this argument is that 
cells carrying the Smc3-Scc1 fusion are viable, implying that the fusion proteins build "real" cohesion as well as entrap chromatin fibers. It is difficult to imagine that their ability to entrap chromatin arises from properties unique to Smc3-Scc1 fusion proteins and not inherent to wild-type cohesin. To explain away their supposedly artifactual ability to entrap chromatin fibers, one must postulate a strange and, for the unsuspecting investigator, malign coincidence, namely that the fusion just happens to create a complex capable of entrapping chromatin. Despite the implausibility of the criticism of the Smc3-Scc1 fusion protein, it is hoped that future experiments will test whether coentrapment also occurs in cells in which Smc3 is not fused to Scc1 at the time of cohesion establishment. The notion that cohesion that holds minichromosomes together in vitro is mediated by coentrapment of sister fibers by cohesin rings, whereas other forms of cohesion are mediated by a very different mechanism, is equally implausible, not to mention ad hoc. More serious, it does not explain how minichromosomes possess a totally different mechanism from real chromosomes in the absence of any obvious evolutionary pressure to produce such a complex property.

What else could be so grievously wrong with the tripartite ring model that one would prefer more complicated and still poorly articulated alternatives involving multimeric complexes? It has been suggested (Skibbens 2010) that the proximity of Smc1 and Smc3 NBDs even in the absence of Sccl is inconsistent with the notion that entrapment depends on bridging of Smc1 and Smc3 NBDs by $\mathrm{Scc} 1$, that the model struggles with the reality that phosphorylation of stromal antigen (SA) proteins, the mammalian orthologs of Scc3, drives dissociation of some cohesin from chromosomes during prophase, and most troubling of all that the model provides no role for Scc3 or Pds5. These are possibly all accurate observations not currently explained by the model, but it is hard to see why they are blatantly inconsistent with it. The model is undoubtedly incomplete (see below) but this is not synonymous with its principle being fundamentally flawed. Words and arguments will not kill the model, but hard facts, i.e., killer experiments will.

\section{THE RING MODEL IS INCOMPLETE}

The real problems with the ring model are twofold. The first is that loopholes remain in the experimental evidence implying that sister minichromosome DNAs are entrapped inside monomeric tripartite rings as opposed to dimeric variants. Final proof will require either more refined biochemical experiments or possibly visualization of the rings holding minichromosomes together by electron or atomic force microscopy. It would also be comforting to know that the sort of cohesion that holds circular minichromosomes together in vitro also holds linear sister chromatids together and that cohesion along chromosome arms obeys the same rules as that conferred by centromeres. The real Achilles heal of the evidence for entrapment is our poor understanding of how Scc1 binds to Smc3 NBDs. Crystal structures exist for the Smc1/Smc3 hinge and the Smc1 NBD-Scc1 interfaces but not for Smc3-Scc1. Scc1 does undoubtedly associate with Smc3 NBDs, but it has so far proved impossible to reconstruct the association with purified components in vitro, which has greatly hindered elucidation of its structure by X-ray crystallography. The reasons for this may have something to do with the possibility that this interface is regulated during the cell cycle. For example, it may be no coincidence that Ecol promotes the establishment of cohesion by acetylating the Smc3 NBD (Ben-Shahar et al. 2008; Unal et al. 2008; Zhang et al. 2008a; Rowland et al. 2009), an event that might alter the stability or conformation of its association with the amino-terminal domain of Scc1. Structural information about the Smc3NBD-Scc1 interface would not only be revealing about its stability, a crucial feature according to the ring model, but would also enable the cross-linking studies to be repeated with complexes lacking a connection between Smc3 and Scc1. The second problem is potentially more serious and concerns the model's incompleteness. As it currently stands, the model does not explain how coentrapment of sister DNAs is generated or maintained.

\section{HOW DO DNAS ENTER THE TRIPARTITE RING?}

Assuming that cohesion is generated by preassembled rings, how do they open and shut to permit DNA entry? Presumably, one of the three interfaces comprising the ring must transiently open. The finding that cohesin retains function after fusion of Smc1 and Smc3 NBDs to Scc1's carboxy- and amino-terminal domains, respectively, suggests that the Smc1/Smc3 hinge is the entry gate (Gruber et al. 2006). It is clearly more than just a dimerization domain required to create V-shaped $\mathrm{Smc} 1 / \mathrm{Smc} 3$ heterodimers because cohesin rings in which $\mathrm{Smc1}$ and $\mathrm{Smc} 3$ hinge domains are replaced by $\mathrm{Mp} 1$ and $\mathrm{p} 14$, which also form very stable pseudosymmetrical dimers, fail completely to associate with chromatin despite being capable of ATP hydrolysis (Gruber et al. 2006). The mouse Smc1/Smc3 hinge crystal structure closely resembles the homodimeric bacterial Thermotoga maritima SMC hinge (Haering et al. 2002; Kurze et al. 2010). In both cases, shallow U-shaped hinge monomers interact to form a pseudo twofold symmetric torus with a small channel in the middle. Remarkably, the channel is positively charged, a feature that, according to modeling, is conserved in SMC hinges from widely different eukaryotic and prokaryotic organisms. A set of amino acid substitutions in budding yeast $\mathrm{Smc1}$ and Smc3 largely eliminate the channel's positive charge without greatly changing the equilibrium association constant. Although the neutralizing mutations permit formation of cohesin rings that associate stably with the genome, they drastically reduce the establishment of cohesion during S phase (Kurze et al. 2010). These data are difficult to reconcile with the notion that the hinge is merely a dimerization domain and suggest that it undergoes a major conformational change, at least during DNA replication. Probably the strongest evidence that the two hinge halves transiently dissociate is the observation that the artificial connection, by addition of rapamycin, of Smc1 and Smc3 hinge domains containing FKBP12 and Frb dimerization domains, respectively, blocks the establish- 
ment but not maintenance of sister chromatid cohesion (Gruber et al. 2006).

Current observations demonstrate that the hinge is not just a dimerization domain and that it has an active role in the establishment of sister chromatid cohesion during $\mathrm{S}$ phase, but they do not yet constitute proof that it is a DNA entry gate. This will require either actual observation of opening, which due to its transient nature will be very difficult in live cells with current technologies, or analysis of the effect of site-specific chemical cross-linking of the type used to demonstrate entrapment of minichromosome DNAs inside cohesin rings.

\section{WHAT HAPPENS TO COHESIN RINGS AT S PHASE?}

Another crucial gap in our understanding is the state of cohesin's association with chromatin before the passage of replication forks. It is assumed that this is also topological, but there is little direct evidence for this. It is an important issue for two reasons. First, there is increasing evidence that cohesin has important functions regulating transcription both in dividing and nondividing cells (Peters et al. 2008; Nasmyth and Haering 2009). Knowing how it associates with unreplicated chromatin will be essential for elucidating how it affects transcription. Second, knowing more about this state may provide insight into the mechanism by which cohesion is established during DNA replication. The ring model envisages two main scenarios by which this comes about: Either rings that have already entrapped unreplicated chromatin fibers are converted during passage of replication forks to those that entrap sister fibers or the rings that entrap sister fibers are derived from a soluble pool and must reload onto chromatin at the time of replication. In the case of the first scenario, the replication apparatus either passes through rings that remain shut once they have associated with unreplicated chromatin or rings associated with unreplicated chromatin reopen during passage of the fork while remaining associated with the replicating chromatin fiber.

Whichever scenario is correct, stable entrapment of sister fibers is accompanied by and dependent on de novo acetylation of a pair of highly conserved lysines (K112 and K113) within Smc3 NBDs by Eco1 (Ben-Shahar et al. 2008; Unal et al. 2008; Zhang et al. 2008a; Rowland et al. 2009). In yeast, Smc3 acetylation is reversed at anaphase by the Hos 1 deacetylase as a consequence of Scc1 cleavage (Beckouet et al. 2010). Smc3 molecules that remain acetylated after mitosis due to Hos1 inactivation cannot generate cohesion during the subsequent $\mathrm{S}$ phase, implying that cohesion establishment depends on de novo acetylation during DNA replication. A key issue surrounding Eco1's function is whether acetylation merely alters the ring to facilitate the establishment of cohesion during $\mathrm{S}$ phase and thereafter has no further function, a model suggested by the finding that Eco1 is dispensable for maintaining cohesion after cells have completed DNA replication (Skibbens et al. 1999; Toth et al. 1999). However, the discovery that Hos1 cannot deacetylate Smc3 until Scc1 is cleaved suggests that the acetyl marks at
K112 and K113 are stable and not turned over appreciably between DNA replication and anaphase. Thus, the acetylation mark could indeed have a postreplicative role. What might this be? The observation that overproduction of Hos1 in M-phase cells induces rapid albeit incomplete Smc3 deacetylation that is accompanied by a reduction of sister chromatid cohesion is possibly an important clue that acetylation actively stabilizes cohesion (Beckouet et al. 2010; Borges et al. 2010). The notion that acetylation "locks" cohesin in a cohesive state (Unal et al. 2008) now warrants serious consideration. That we do not understand the role or indeed mechanism by which Smc3 acetylation promotes the establishment or maintenance of cohesion is another demonstration of the paucity of our knowledge. Another is the fact that we have little or no idea how cohesin's Scc3 and Pds5 subunits help to maintain cohesion in postreplicative cells nor how its Wapl subunit (Gandhi et al. 2006; Kueng et al. 2006) together with Scc3 phosphorylation (Hauf et al. 2005) promotes dissociation from chromosome arms in vertebrates of a large fraction of cohesin during prophase and prometaphase in the absence of Scc1 cleavage. We also have little idea as to sororin's role (Rankin et al. 2005; Schmitz et al. 2007). If the ring model is correct, Pds5, Scc3, sororin, and Wapl must somehow regulate, either positively or negatively, the ring opening, an event that would permit DNA escape.

\section{THE SCC2/4 COMPLEX AND THE COHESIN-LOADING REACTION}

Yet another area of ignorance concerns the mechanism by which cohesin associates with chromosomes, a process that barring mitosis in organisms other then yeast occurs throughout the cell cycle and is therefore not synonymous with the establishment of cohesion. Association requires a separate loading complex composed of the Scc2 and Scc4 (also known as Nipbl and Mau2 in vertebrates) proteins (Ciosk et al. 2000; Gillespie and Hirano 2004; Takahashi et al. 2004). The molecular mechanism by which the Scc2/4 complex helps cohesin to load onto chromosomes is poorly understood, partly because the reaction occurs rapidly inside cells and has therefore hitherto defied dissection into discrete steps and partly because it is not known where on chromosomes loading takes place. With a diameter of $30 \mathrm{~nm}$ or more, cohesin rings should be capable of sliding along one or more $10-\mathrm{nm}$ chromatin fibers, a process that clearly takes place in vitro. If this also takes place in vivo, the eventual distribution of cohesin as measured by chromatin immunoprecipitation (ChIP) studies may not in fact reflect where loading took place. The suggestion, either from chromosome spreads (Ciosk et al. 2000) or ChIP-Chip studies (Lengronne et al. 2004), that Scc2/4 and cohesin reside at different genomic locations in yeast has been taken to mean that cohesin slides from "loading sites" occupied by Scc2/4 to its final chromosomal destination. However, the conclusion that Scc $2 / 4$ and cohesin have different genomic distributions has since been disputed (Kogut et al. 2009). More serious, there is hitherto no evidence that sites occupied by Scc $2 / 4$ represent loci at which cohesin is first loaded onto chromosomes. 
Cohesin is an ABC-like ATPase. Binding of ATP to Smc1 and Smc3 NBDs is thought to induce their engagement and hydrolysis to drive them apart. We reasoned that blocking the ATP-binding/hydrolysis cycle at a crucial point might cause cohesin to accumulate at an intermediate stage before the chromatin entrapment process. Interestingly, Smc1 or Smc3 variants trapped in a transition state with NBDs engaged (Arumugam et al. 2003, 2006) accumulate to high levels at core centromeres, which are known to promote cohesin's recruitment to a wide swathe of pericentric sequences. The instability of this association and its colocalization with and dependence on Scc2/4 indicates that transition-state cohesin complexes undergo an early step in the loading reaction but fail to entrap chromatin fibers (Hu et al. 2010). The finding that transition-state complexes accumulate at core centromeres but not with pericentric sequences implies that DNA entrapment leads to cohesin's translocation for a very considerable distance along chromatin fibers. If we assume that association with Scc2/4 loading sites of cohesin complexes defective in NDB disengagement corresponds to a state, albeit a transient one, normally entered into by wild-type complexes, investigation of which aspects of cohesin are necessary for entering into this state should be informative about early steps in the cohesin-loading process. Interestingly, the accumulation of transition-state complexes at core centromeres depends on Scc3 but not Pds5 or Wapl. The implication is that Scc3 has key roles not only in maintaining cohesion once established but also during an early step in loading cohesin onto chromosomes, possibly long before cells even enter $\mathrm{S}$ phase. The molecular mechanism by which the Scc2/4 complex together with Scc3 promotes cohesin loading remains completely mysterious.

\section{SUMMARY}

There is now overwhelming evidence that cohesin alone provides the cohesion between sister chromatids capable of resisting spindle forces and thereby promoting biorientation. We have a working model for how it performs this task, namely coentrapment of sister DNAs inside a tripartite ring made up of cohesin's Scc1, Smc1, and Smc3 subunits. This model has made a number of critical predictions that have been experimentally verified but remains work in progress. Opening of the cohesin ring following cleavage of Scc1 by separase triggers sister chromatid disjunction but is insufficient for other aspects of anaphase chromosome movements that are instead mediated directly or indirectly by Cdk1 down-regulation. Cdk1 downregulation and separase activation are orchestrated through ubiquitinylation by the APC/C of cyclin B, Cdk1's regulatory subunit, and securin, an inhibitory chaperone of separase. The key role that cohesin cleavage has during Flemming's indirect nuclear division has been highlighted by experiments in which metaphase cells can be induced to produce a pair of daughter nuclei merely by injecting an inhibitor of Cdk1 and a protease capable of cleaving Scc1.

Although first discovered for its role during mitosis, cohesin also has key roles in promoting double-strand break repair and in regulating transcription during interphase in dividing and nondividing cells. It is important to stress that we still have a very poor grasp of how cohesin builds cohesion, let alone how it regulates transcription during development. Further understanding, which will lay solid foundations for the entire field, will depend on rigorous structural and mechanistic studies, which given cohesin's complicated and flexible structure and the complexities of its association with chromatin are difficult, to say the least. Elucidating how cohesin and its siblings condensin and the Smc5/6 complex actually function will be a wonderful challenge for enzymologists prepared to investigate their properties in vitro as well as in vivo. Furthermore, understanding the mechanisms by which cohesion is established and maintained may be of great importance to one of the most pressing medical problems of the modern age, namely age-related infertility in women. If cohesion can only be established during DNA replication (Uhlmann and Nasmyth 1998; Haering et al. 2004), the cohesin that holds bivalent chromosomes together in oocytes and necessary for the meiotic divisions that occur in mature adults may have been deposited before birth, which is when meiotic DNA replication in females takes place. The recent finding that bivalents fall apart due possibly to loss of cohesin in oocytes from old mice (Chiang et al. 2010; Lister et al. 2010) suggests that a failure to maintain cohesive structures after several decades could contribute to the chromosome mis-segregation responsible for age-related aneuploidy and infertility.

\section{ACKNOWLEDGMENTS}

We thank Christian Hearing (EMBL) for the model presented in Figure 3. Work in the laboratory of K.N. is supported by the Wellcome Trust, Cancer Research UK, and the Medical Research Council (MRC).

\section{REFERENCES}

Adams RR, Carmena M, Earnshaw WC. 2001. Chromosomal passengers and the (aurora) ABCs of mitosis. Trends Cell Biol 11: 49-54.

Arumugam P, Gruber S, Tanaka K, Haering CH, Mechtler K, Nasmyth K. 2003. ATP hydrolysis is required for cohesin's association with chromosomes. Curr Biol 13: 1941-1953.

Arumugam P, Nishino T, Haering CH, Gruber S, Nasmyth K. 2006. Cohesin's ATPase activity is stimulated by the C-terminal Winged-Helix domain of its kleisin subunit. Curr Biol 16: 1998-2008

Baker BS, Carpenter AT, Ripoll P. 1978. The utilization during mitotic cell division of loci controlling meiotic recombination and disjunction in Drosophila melanogaster. Genetics 90: 531-578.

Baum P, Yip C, Goetsch L, Byers B. 1988. A yeast gene essential for regulation of spindle pole duplication. Mol Cell Biol 8: 5386-5397.

Beckouet F, Hu B, Roig MB, Sutani T, Komata M, Uluocak P, Katis VL, Shirahige K, Nasmyth K. 2010. An Smc3 acetylation cycle is essential for establishment of sister chromatid cohesion. Mol Cell 39: 689-699.

Ben-Shahar TR, Heeger S, Lehane C, East P, Flynn H, Skehel M, Uhlmann F. 2008. Eco1-dependent cohesin acetylation during establishment of sister chromatid cohesion. Science 321: 563566.

Borges V, Lehane C, Lopez-Serra L, Flynn H, Skehel M, Rolef 
Ben-Shahar T, Uhlmann F. 2010. Hos1 deacetylates Smc3 to close the cohesin acetylation cycle. Mol Cell 39: 677-688.

Chiang T, Duncan FE, Schindler K, Schultz RM, Lampson MA. 2010. Evidence that weakened centromere cohesion is a leading cause of age-related aneuploidy in oocytes. Curr Biol 20: 15221528.

Ciferri C, Pasqualato S, Screpanti E, Varetti G, Santaguida S, Dos Reis G, Maiolica A, Polka J, De Luca JG, De Wulf P, et al. 2008. Implications for kinetochore-microtubule attachment from the structure of an engineered Ndc80 complex. Cell 133: 427-439.

Ciosk R, Zachariae W, Michaelis C, Shevchenko A, Mann M, Nasmyth K. 1998. An Esp1/Pds1 complex regulates loss of sister chromatid cohesion at the metaphase to anaphase transition in yeast. Cell 93: 1067-1076.

Ciosk R, Shirayama M, Shevchenko A, Tanaka T, Toth A, Shevchenko A, Nasmyth K. 2000. Cohesin's binding to chromosomes depends on a separate complex consisting of Scc2 and Scc4 proteins. Mol Cell 5: 243-254.

Cohen-Fix O, Peters J-M, Kirschner MW, Koshland D. 1996. Anaphase initiation in Saccharomyces cerevisiae is controlled by the APC-dependent degradation of the anaphase inhibitor Pds1p. Genes Dev 10: 3081-3093.

Culotti J, Hartwell LH. 1971. Genetic control of the cell division cycle in yeast. 3. Seven genes controlling nuclear division. Exp Cell Res 67: 389-401.

Dinardo S, Voelkel KA, Sternglanz RL. 1984. DNA topoisomerase mutant of $S$. cerevisiae: Topoisomerase II is required for segregation of daughter molecules at the termination of DNA replication. Proc Natl Acad Sci 81: 2616-2620.

Evans T, Rosenthal ET, Youngbloom J, Distel D, Hunt T. 1983. Cyclin: A protein specified by maternal mRNA in sea urchin eggs that is destroyed at each cleavage division. Cell 33: 389-396.

Flemming W. 1880. Beiträge zur Kenntnisse der Zelle und ihrer Lebenserscheinungen. Archiv Mikrosk Anat 18: 151-259.

Funabiki H, Kumada K, Yanagida M. 1996a. Fission yeast Cut1 and Cut2 are essential for sister chromatid separation, concentrate along the metaphase spindle and form large complexes. EMBO J 15: 6617-6628.

Funabiki H, Yamano H, Kumada K, Nagao K, Hunt T, Yanagida M. 1996b. Cut2 proteolysis required for sister-chromatid separation in fission yeast. Nature 381: 438-441.

Gall JG. 1963. Kinetics of deoxyribonuclease action on chromosomes. Nature 198: 36-38.

Gandhi R, Gillespie PJ, Hirano T. 2006. Human Wapl is a cohesinbinding protein that promotes sister-chromatid resolution in mitotic prophase. Curr Biol 16: 2406-2417.

Gillespie PJ, Hirano T. 2004. Scc2 couples replication licensing to sister chromatid cohesion in Xenopus egg extracts. Curr Biol 14: 1598-1603.

Glotzer M, Murray AW, Kirschner MW. 1991. Cyclin is degraded by the ubiquitin pathway (comments). Nature 349: 132-138.

Goldstein LSB. 1980. Mechanisms of chromosome orientation revealed by two meiotic mutants in Drosophila melanogaster. Chromosoma 78: 79-111.

Gruber S, Haering CH, Nasmyth K. 2003. Chromosomal cohesin forms a ring. Cell 112: 765-777.

Gruber S, Arumugam P, Katou Y, Kuglitsch D, Helmhart W, Shirahige K, Nasmyth K. 2006. Evidence that loading of cohesin onto chromosomes involves opening of its SMC hinge. Cell 127: 523-537.

Guacci V, Koshland D, Strunnikov A. 1997. A direct link between sister chromatid cohesion and chromosome condensation revealed through analysis of MCD1 in S. cerevisiae. Cell 91: 4757.

Haering CH, Lowe J, Hochwagen A, Nasmyth K. 2002. Molecular architecture of SMC proteins and the yeast cohesin complex. Mol Cell 9: 773-788.

Haering CH, Schoffnegger D, Nishino T, Helmhart W, Nasmyth K, Lowe J. 2004. Structure and stability of cohesin's Smc1kleisin interaction. Mol Cell 15: 951-964.

Haering CH, Farcas A, Arumugam P, Metson J, Nasmyth K. 2008. The cohesin ring concatenates sister DNAs. Nature 454: 297301.
Hartman T, Stead K, Koshland D, Guacci V. 2000. Pds5p is an essential chromosomal protein required for both sister chromatid cohesion and condensation in Saccharomyces cerevisiae. J Cell Biol 151: 613-626.

Hassold T, Hunt P. 2001. To err (meiotically) is human: the genesis of human aneuploidy. Nat Rev Genet 2: 280-291.

Hauf S, Roitinger E, Koch B, Dittrich CM, Mechtler K, Peters JM. 2005. Dissociation of cohesin from chromosome arms and loss of arm cohesion during early mitosis depends on phosphorylation of SA2. PLoS Biol 3: e69.

Heidinger-Pauli JM, Onn I, Koshland D. 2010. Genetic evidence that the acetylation of the Smc3p subunit of cohesin modulates its ATP-bound state to promote cohesion establishment in Saccharomyces cerevisiae. Genetics 185: 1249-1256.

Hershko A, Ganoth D, Pehrson J, Palazzo RE, Cohen LH. 1991. Methylated ubiquitin inhibits cyclin degradation in clam embryo extracts. J Biol Chem 266: 16376-16379.

Hirano T. 2005. Condensins: Organizing and segregating the genome. Curr Biol 15: R265-R275.

Hirano M, Hirano T. 2002. Hinge-mediated dimerization of SMC protein is essential for its dynamic interaction with DNA. EMBO J 21: 5733-5744.

Holloway SL, Glotzer M, King RW, Murray AW. 1993. Anaphase is initiated by proteolysis rather than by the inactivation of maturation-promoting factor. Cell 73: 1393-1402.

Holm C, Goto T, Wang JC, Botstein D. 1985. DNA topoisomerase II is required at the time of mitosis in yeast. Cell 41: 553-563.

Holm C, Stearns T, Botstein D. 1989. DNA topoisomerase II must act at mitosis to prevent nondisjunction and chromosome breakage. Mol Cell Biol 9: 159-168.

Hopfner KP, Tainer JA. 2003. Rad50/SMC proteins and ABC transporters: Unifying concepts from high-resolution structures. Curr Opin Struct Biol 13: 249-255.

Hu B, Itoh T, Mishra A, Katoh Y, Chan KL, Upcher W, Godlee C, Roig MB, Shirahige K, Nasmyth K. 2010. Identification of an intermediate step in the cohesin chromosome loading reaction. Curr Biol (in press).

Huang X, Andreu-Vieyra CV, York JP, Hatcher R, Lu T, Matzuk MM, Zhang P. 2008. Inhibitory phosphorylation of separase is essential for genome stability and viability of murine embryonic germ cells. PLoS Biol 6: e15.

Huang X, Andreu-Vieyra CV, Wang M, Cooney AJ, Matzuk MM, Zhang P. 2009. Preimplantation mouse embryos depend on inhibitory phosphorylation of separase to prevent chromosome missegregation. Mol Cell Biol 29: 1498-1505.

Irniger S, Piatti S, Michaelis C, Nasmyth K. 1995. Genes involved in sister chromatid separation are needed for B-type cyclin proteolysis in budding yeast. Cell 81: 269-278.

Ishiguro T, Tanaka K, Sakuno T, Watanabe Y. 2010. ShugoshinPP2A counteracts casein-kinase-1-dependent cleavage of Rec8 by separase. Nat Cell Biol 12: 500-506.

Ivanov D, Nasmyth K. 2005. A topological interaction between cohesin rings and a circular minichromosome. Cell 122: 849-860.

Ivanov D, Nasmyth K. 2007. A physical assay for sister chromatid cohesion in vitro. Mol Cell 27: 300-310.

Ivanov D, Schleiffer A, Eisenhaber F, Mechtler K, Haering CH, Nasmyth K. 2002. Ecol is a novel acetyltransferase that can acetylate proteins involved in cohesion. Curr Biol 12: 1-20.

Katis VL, Lipp JJ, Imre R, Bogdanova A, Okaz E, Habermann B, Mechtler K, Nasmyth K, Zachariae W. 2010. Rec8 phosphorylation by casein kinase 1 and Cdc7-Dbf4 kinase regulates cohesin cleavage by separase during meiosis. Dev Cell 18: 397-409.

Kerrebrock AW, Moore DP, Wu JS, Orr-Weaver TL. 1995. MeiS332, a Drosophila protein required for sister-chromatid cohesion, can localize to meiotic centromere regions (comments). Cell 83: 247-256.

King RW, Peters J, Tugendreich S, Rolfe M, Hieter P, Kirschner MW. 1995. A 20S complex containing CDC27 and CDC16 catalyzes the mitosis-specific conjugation of ubiquitin to cyclin B. Cell 81: 279-288.

Kitajima TS, Kawashima SA, Watanabe Y. 2004. The conserved kinetochore protein shugoshin protects centromeric cohesion 
during meiosis. Nature 427: 510-517.

Kogut I, Wang J, Guacci V, Mistry RK, Megee PC. 2009. The $\mathrm{Scc} 2 / \mathrm{Scc} 4$ cohesin loader determines the distribution of cohesin on budding yeast chromosomes. Genes Dev 23: 2345-2357.

Koshland D, Hartwell L. 1987. The structure of sister minichromosome DNA before anaphase in Saccharomyces cerevisiae. Science 238: 1713-1716.

Krantz ID, McCallum J, DeScipio C, Kaur M, Gillis LA, Yaeger D, Jukofsky L, Wasserman N, Bottani A, Morris CA, et al. 2004. Cornelia de Lange syndrome is caused by mutations in NIPBL, the human homolog of Drosophila melanogaster Nipped-B. Nat Genet 36: 631-635.

Kueng S, Hegemann B, Peters BH, Lipp JJ, Schleiffer A, Mechtler K, Peters JM. 2006. Wapl controls the dynamic association of cohesin with chromatin. Cell 127: 955-967.

Kurze A, Michie KA, Dixon SE, Mishra A, Itoh T, Khalid S, Strmecki L, Shirahige K, Haering CH, Lowe J, et al. 2010. A positively charged channel within the Smc1/Smc3 hinge required for sister chromatid cohesion. $E M B O J$ (in press).

Lam WW, Peterson EA, Yeung M, Lavoie BD. 2006. Condensin is required for chromosome arm cohesion during mitosis. Genes Dev 20: 2973-2984.

Lengronne A, Katou Y, Mori S, Yokobayashi S, Kelly GP, Itoh T, Watanabe Y, Shirahige K, Uhlmann F. 2004. Cohesin relocation from sites of chromosomal loading to places of convergent transcription. Nature 430: 573-578.

Lindon C, Pines J. 2004. Ordered proteolysis in anaphase inactivates Plk1 to contribute to proper mitotic exit in human cells. $J$ Cell Biol 164: 233-241.

Lister LM, Kouznetsova A, Hyslop LA, Kalleas D, Pace SL, Barel JC, Nathan A, Floros V, Adelfalk C, Watanabe Y, et al. 2010. Age-related meiotic segregation errors in Mammalian oocytes are preceded by depletion of cohesin and Sgo2. Curr Biol 20: 1511-1521.

Liu D, Vader G, Vromans MJ, Lampson MA, Lens SM. 2009. Sensing chromosome bi-orientation by spatial separation of aurora $\mathrm{B}$ kinase from kinetochore substrates. Science 323: 1350-1353.

Losada A, Hirano M, Hirano T. 1998. Identification of Xenopus SMC protein complexes required for sister chromatid cohesion. Genes Dev 12: 1986-1997.

Lucas I, Germe T, Chevrier-Miller M, Hyrien O. 2001. Topoisomerase II can unlink replicating DNA by precatenane removal. EMBO J 20: 6509-6519.

Marston AL, Tham WH, Shah H, Amon A. 2004. A genome-wide screen identifies genes required for centromeric cohesion. Science 303: 1367-1370.

McGrew JT, Goetsch L, Byers B, Baum P. 1992. Requirement for ESP1 in the nuclear division of S. cerevisiae. Mol Biol Cell 3: 1443-1454.

McGuinness BE, Hirota T, Kudo NR, Peters JM, Nasmyth K. 2005. Shugoshin prevents dissociation of cohesin from centromeres during mitosis in vertebrate cells. PLoS Biol 3: 433449.

Mc Intyre J, Muller EG, Weitzer S, Snydsman BE, Davis TN, Uhlmann F. 2007. In vivo analysis of cohesin architecture using FRET in the budding yeast Saccharomyces cerevisiae. EMBO J 26: 3783-3793.

Melby TE, Ciampaglio CN, Briscoe G, Erickson HP. 1998. The symmetrical structure of structural maintainance of chromosomes (SMC) and MukB proteins: Long, antiparallel coiled coils, folded at a flexible hinge. J Cell Biol 142: 1595-1604.

Meselson M, Stahl FW. 1958. The replication of DNA in Escherichia coli. Proc Natl Acad Sci 44: 671-682.

Michaelis C, Ciosk R, Nasmyth K. 1997. Cohesins: Chromosomal proteins that prevent premature separation of sister chromatids. Cell 91: 35-45.

Mirchenko L, Uhlmann F. 2010. Sli15(INCENP) dephosphorylation prevents mitotic checkpoint reengagement due to loss of tension at anaphase onset. Curr Biol 20: 1396-1401.

Miyazaki WY, Orr-Weaver TL. 1994. Sister-chromatid cohesion in mitosis and meiosis. Annu Rev Genet 28: 167-187.

Mole-Bajer J. 1958. Cine-micrographic analysis of C-mitosis in endosperm. Chromosoma 9: 332-358.
Moore DP, Page AW, Tang TT, Kerrebrock AW, Orr-Weaver TL. 1998. The cohesion protein MEI-S332 localizes to condensed meiotic and mitotic centromeres until sister chromatids separate. J Cell Biol 140: 1003-1012.

Murray AW, Szostak JW. 1985. Chromosome segregation in mitosis and meiosis. Annu Rev Cell Biol 1: 289-315.

Murray AW, Solomon MJ, Kirschner MW. 1989. The role of cyclin synthesis and degradation in the control of maturation promoting factor activity. Nature 339: 280-286.

Musacchio A, Salmon ED. 2007. The spindle-assembly checkpoint in space and time. Nat Rev Mol Cell Biol 8: 379-393.

Nasmyth K. 2001. Disseminating the genome: Joining, resolving, and separating sister chromatids during mitosis and meiosis. Annu Rev Genet 35: 673-745.

Nasmyth K, Haering CH. 2009. Cohesin: Its roles and mechanisms. Annu Rev Genet 43: 525-528.

Nicklas RB. 1967. Chromosome micromanipulation. II. Induced reorientation and the experimental control of segregation in meiosis. Chromosoma 21: 17-50.

Nicklas RB. 1988. The forces that move chromosomes in mitosis. Annu Rev Biophys Biophys Chem 17: 431-449.

Oliveira RA, Hamilton RS, Pauli A, Davis I, Nasmyth K. 2010. Cohesin cleavage and $\mathrm{Cdk}$ inhibition trigger formation of daughter nuclei. Nat Cell Biol 12: 185-192.

Palframan WJ, Meehl JB, Jaspersen SL, Winey M, Murray AW. 2006. Anaphase inactivation of the spindle checkpoint. Science 313: 680-684.

Panizza S, Tanaka T, Hohchwagen A, Eisenhaber F, Nasmyth K. 2000. Pds5 cooperates with cohesin in maintaining sister chromatid cohesion. Curr Biol 10: 1557-1564.

Parry DH, O'Farrell PH. 2001. The schedule of destruction of three mitotic cyclins can dictate the timing of events during exit from mitosis. Curr Biol 11: 671-683.

Parry DH, Hickson GR, O'Farrell PH. 2003. Cyclin B destruction triggers changes in kinetochore behavior essential for successful anaphase. Curr Biol 13: 647-653.

Pauli A, Althoff F, Oliveira RA, Heidmann S, Schuldiner O, Lehner CF, Dickson BJ, Nasmyth K. 2008. Cell-type-specific TEV protease cleavage reveals cohesin functions in Drosophila neurons. Dev Cell 14: 239-251.

Peters JM. 2006. The anaphase promoting complex/cyclosome: A machine designed to destroy. Nat Rev Mol Cell Biol 7: 644-656.

Peters JM, Tedeschi A, Schmitz J. 2008. The cohesin complex and its roles in chromosome biology. Genes Dev 22: 3089-3114.

Rabitsch KP, Gregan J, Schleiffer A, Javerzat JP, Eisenhaber F, Nasmyth K. 2004. Two fission yeast homologs of Drosophila MeiS332 are required for chromosome segregation during meiosis I and II. Curr Biol 14: 287-301.

Rankin S, Ayad NG, Kirschner MW. 2005. Sororin, a substrate of the anaphase-promoting complex, is required for sister chromatid cohesion in vertebrates. Mol Cell 18: 185-200.

Rieder CL. 1991. Mitosis: Towards a molecular understanding of chromosome behavior. Curr Opin Cell Biol 3: 59-66.

Roux W. 1883. Ueber die bedeutung der kerntheilungsfiguren. Engelmann, Leipzig.

Rowland BD, Roig MB, Nishino T, Kurze A, Uluocak P, Mishra A, Beckouet F, Underwood P, Metson J, Imre R, et al. 2009. Building sister chromatid cohesion: smc3 acetylation counteracts an antiestablishment activity. Mol Cell 33: 763-774.

Salic A, Waters JC, Mitchison TJ. 2004. Vertebrate shugoshin links sister centromere cohesion and kinetochore microtubule stability in mitosis. Cell 118: $567-578$.

Schleiffer A, Kaitna S, Maurer-Stroh S, Glotzer M, Nasmyth K, Eisenhaber F. 2003. Kleisins: A superfamily of bacterial and eukaryotic SMC protein partners. Mol Cell 11: 571-575.

Schmitz J, Watrin E, Lenart P, Mechtler K, Peters JM. 2007. Sororin is required for stable binding of cohesin to chromatin and for sister chromatid cohesion in interphase. Curr Biol 17: 630-636.

Seitan VC, Banks P, Laval S, Majid NA, Dorsett D, Rana A, Smith J, Bateman A, Krpic S, Hostert A, et al. 2006. Metazoan Scc4 homologs link sister chromatid cohesion to cell and axon migration guidance. PLoS Biol 4: e242. 
Shimada K, Gasser SM. 2007. The origin recognition complex functions in sister-chromatid cohesion in Saccharomyces cerevisiae. Cell 128: 85-99.

Shirayama M, Zachariae W, Ciosk R, Nasmyth K. 1998. The Pololike kinase Cdc5p and the WD-repeat protein Cdc20p/Fizzy are regulators and substrates of the anaphase promoting complex in Saccharomyces cerevisiae. EMBO J 17: 1336-1349.

Shirayama M, Toth A, Galova M, Nasmyth K. 1999. APC(Cdc20) promotes exit from mitosis by destroying the anaphase inhibitor Pds1 and cyclin Clb5. Nature 402: 203-207.

Skibbens RV. 2010. Buck the establishment: reinventing sister chromatid cohesion. Trends Cell Biol 20: 507-513.

Skibbens RV, Corson LB, Koshland D, Hieter P. 1999. Ctf7p is essential for sister chromatid cohesion and links mitotic chromosome structure to the DNA replication machinery. Genes Dev 13: $307-319$

Stemmann O, Zou H, Gerber SA, Gygi SP, Kirschner MW. 2001. Dual inhibition of sister chromatid separation at metaphase. Cell 107: 715-726.

Stratmann R, Lehner CF. 1996. Separation of sister chromatids in mitosis requires the Drosophila pimples product, a protein degraded after the metaphase/anaphase transition. Cell 84: 25-35.

Sudakin V, Ganoth D, Dahan A, Heller H, Hershko J, Luca FC, Ruderman JV, Hershko A. 1995. The cyclosome, a large complex containing cyclin-selective ubiquitin ligase activity, targets cyclins for destruction at the end of mitosis. Mol Biol Cell 6: 185198.

Sundin O, Varshavsky A. 1981. Arrest of segregation leads to accumulation of highly intertwined catenated dimers: Dissection of the final stages of SV40 DNA replication. Cell 25: 659-669.

Surana U, Amon A, Dowzer C, McGrew J, Byers B, Nasmyth K. 1993. Destruction of the CDC28/CLB mitotic kinase is not required for the metaphase to anaphase transition in budding yeast. EMBO J 12: 1969-1978.

Takahashi TS, Yiu P, Chou MF, Gygi S, Walter JC. 2004. Recruitment of Xenopus Scc2 and cohesin to chromatin requires the pre-replication complex. Nat Cell Biol 6: 991-996.

Tanaka T, Rachidi N, Janke C, Pereira G, Galova M, Schiebel E, Stark MJR, Nasmyth K. 2002. Evidence that the Ipl1-Sli15 (Aurora kinase-INCENP) complex promotes chromosome bi-orientation by altering kinetochore-spindle pole connections. Cell 108: $317-327$.

Taylor JH, Woods PS, Hughes WL. 1957. The organization and duplication of chromosomes as revealed by autoradiographic studies using tritium-labeled thymidine. Proc Natl Acad Sci 43: $122-128$.

Tonkin ET, Wang TJ, Lisgo S, Bamshad MJ, Strachan T. 2004. NIPBL, encoding a homolog of fungal Scc2-type sister chromatid cohesion proteins and fly Nipped-B, is mutated in Cornelia de Lange syndrome. Nat Genet 36: 636-641.

Toth A, Ciosk R, Uhlmann F, Galova M, Schleifer A, Nasmyth K. 1999. Yeast cohesin complex requires a conserved protein, Ecolp (Ctf7), to establish cohesion between sister chromatids during DNA replication. Genes Dev 13: 320-333.

Townsley FM, Aristarkhov A, Beck S, Hershko A, Ruderman JV. 1997. Dominant-negative cyclin-selective ubiquitin carrier protein E2-C/UbcH10 blocks cells in metaphase. Proc Natl Acad Sci 94: 2362-2367.

Uhlmann F, Nasmyth K. 1998. Cohesion between sister chromatids must be established during DNA replication. Curr Biol 8: 10951101.

Uhlmann F, Lottspeich F, Nasmyth K. 1999. Sister chromatid separation at anaphase onset is promoted by cleavage of the cohesin subunit Scc1p. Nature 400: 37-42.
Uhlmann F, Wernic D, Poupart MA, Koonin E, Nasmyth K. 2000. Cleavage of cohesin by the CD clan protease separin triggers anaphase in yeast. Cell 103: 375-386.

Unal E, Heidinger-Pauli JM, Kim W, Guacci V, Onn I, Gygi SP, Koshland DE. 2008. A molecular determinant for the establishment of sister chromatid cohesion. Science 321: 566-569.

Uzawa S, Samejima I, Hirano T, Tanaka K, Yanagida M. 1990. The fission yeast cut $1+$ gene regulates spindle pole body duplication and has homology to the budding yeast ESP1 gene. Cell 62: 913-925.

Vazquez-Novelle MD, Petronczki M. 2010. Relocation of the chromosomal passenger complex prevents mitotic checkpoint engagement at anaphase. Curr Biol 20: 1402-1407.

Vega H, Waisfisz Q, Gordillo M, Sakai N, Yanagihara I, Yamada M, van Gosliga D, Kayserili H, Xu C, Ozono K, et al. 2005. Roberts syndrome is caused by mutations in $\mathrm{ESCO} 2$, a human homolog of yeast ECO1 that is essential for the establishment of sister chromatid cohesion. Nat Genet 37: 468-470.

Waizenegger I, Hauf S, Meinke A, Peters JM. 2000. Two distinct pathways remove mammalian cohesin from chromosome arms in prophase and from centromeres in anaphase. Cell 103: 399410.

Wang Z, Yu R, Melmed S. 2001. Mice lacking pituitary tumor transforming gene show testicular and splenic hypoplasia, thymic hyperplasia, thrombocytopenia, aberrant cell cycle progression, and premature centromere division. Mol Endocrinol 15: $1870-1879$.

Watrin E, Schleiffer A, Tanaka K, Eisenhaber F, Nasmyth K, Peters JM. 2006. Human Scc4 is required for cohesin binding to chromatin, sister-chromatid cohesion, and mitotic progression. Curr Biol 16: 863-874.

Watson JD, Crick FHC. 1953. Genetic implications of the structure of deoxyribonucleic acid. Nature 171: 964-967.

Weitzer S, Lehane C, Uhlmann F. 2003. A model for ATP hydrolysis-dependent binding of cohesin to DNA. Curr Biol 13: 19301940.

Woo JS, Lim JH, Shin HC, Suh MK, Ku B, Lee KH, Joo K, Robinson H, Lee J, Park SY, et al. 2009. Structural studies of a bacterial condensin complex reveal ATP-dependent disruption of intersubunit interactions. Cell 136: 85-96.

Xu Z, Cetin B, Anger M, Cho US, Helmhart W, Nasmyth K, Xu W. 2009. Structure and function of the PP2A-shugoshin interaction. Mol Cell 35: 426-441.

Yamamoto A, Guacci V, Koshland D. 1996a. Pds1p is required for faithful execution of anaphase in the yeast, Saccharomyces cerevisiae. J Cell Biol 133: 85-97.

Yamamoto A, Guacci V, Koshland D. 1996b. Pds1p, an inhibitor of anaphase in budding yeast, plays a critical role in the APC and checkpoint pathways. $J$ Cell Biol 133: 99-110.

Yanagida M. 2009. Clearing the way for mitosis: Is cohesin a target? Nat Rev Mol Cell Biol 10: 489-496.

Zachariae W, Nasmyth K. 1996. TPR proteins required for anaphase progression mediate ubiquitination of mitotic B-type cyclins in yeast. Mol Biol Cell 7: 791-801.

Zachariae W, Shin TH, Galova M, Obermaier B, Nasmyth K. 1996. Identification of subunits of the anaphase-promoting complex of Saccharomyces cerevisiae. Science 274: 1201-1204.

Zhang J, Shi X, Li Y, Kim BJ, Jia J, Huang Z, Yang T, Fu X, Jung SY, Wang Y, et al. 2008a. Acetylation of Smc3 by Eco1 is required for $\mathrm{S}$ phase sister chromatid cohesion in both human and yeast. Mol Cell 31: 143-151.

Zhang N, Kuznetsov SG, Sharan SK, Li K, Rao PH, Pati D. 2008b. A handcuff model for the cohesin complex. J Cell Biol 183: 1019-1031. 


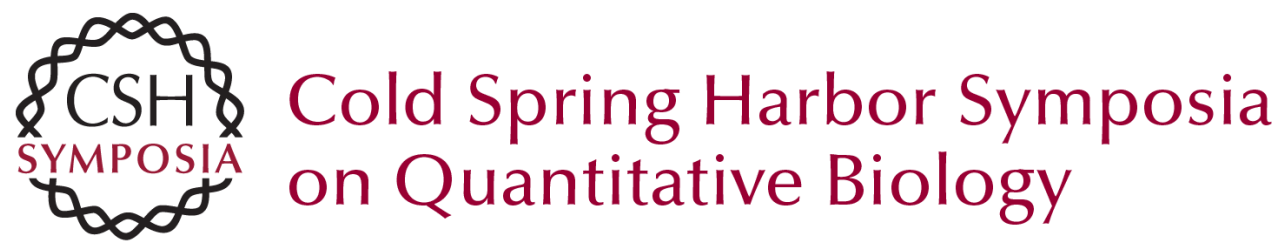

\section{Splitting the Nucleus: What's Wrong with the Tripartite Ring Model?}

K. Nasmyth and R.A. Oliveira

Cold Spring Harb Symp Quant Biol 2010 75: 375-388 originally published online January 5, 2011 Access the most recent version at doi:10.1101/sqb.2010.75.019

References This article cites 134 articles, 34 of which can be accessed free at: http://symposium.cshlp.org/content/75/375.full.html\#ref-list-1

License

Email Alerting Receive free email alerts when new articles cite this article - sign up in the box at the Service top right corner of the article or click here.

To subscribe to Cold Spring Harbor Symposia on Quantitative Biology go to:

http://symposium.cshlp.org/subscriptions 